\title{
Christoph F Dietrich summarises the DEGUM obituary of Gerhard Rettenmaier published in Issue 1 this year
}

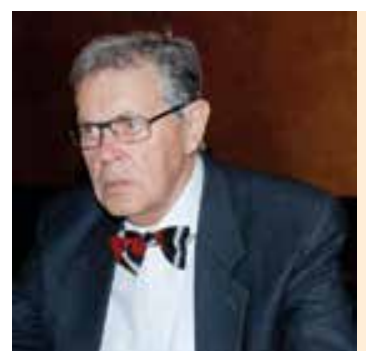

Prof. Dr.

Gerhard

Rettenmaier

Prof. Dr. Gerhard Rettenmaier, a musician and pioneer in ultrasound, introduced ultrasound in internal medicine. His oftencited mission was that "ultrasound is a continuation of the physical examination by other means". He was a founding member of the "Deutsche Arbeitsgemeinschaft für Ultraschalldiagnostik" (German Association for Ultrasound Diagnostics) evolving in 1977 into the "Deutsche Gesellschaft für Ultraschall in der Medizin" (DEGUM, German Society for Ultrasound in Medicine). As early as 1967/ 1968 he introduced world famous "Vidoson" representing real-time B-mode imaging. He trained thousands of doctors in many fields of internal medicine. He was co-founder of our successful journal "Ultraschall in der Medizin". Both patients and colleagues appreciated his knowledge and didactic capacities. We are truly sad to say goodbye to a polymath, great teacher and generalist. 